\title{
Effects of 11-ketotestosterone on genital papilla morphology in the sex changing fish Lythrypnus dalli
}

\author{
S. L. Carlisle*, S. K. Marxer-Miller*, A. V. M. Canario ${ }^{\dagger}$, \\ R. F. Oliveirat, L. Carneiroł And M. S. Grober*q \\ *Department of Life Sciences, Arizona State University West, P.O. Box 37100, Phoenix, \\ Arizona, 85069-7100, U.S.A.; †Centro de Ciencias do Mar, Universidade do Algarve, \\ Campus de Gambelas, 8000 Faro, Portugal and \$Unidade de Investigao em Eco-Etologia, \\ Instituto Superior de Psicologia Aplicada, R. Jardim do Tabaco 44, 1100 Lisboa, \\ Portugal
}

(Received 16 July 1999, Accepted 28 March 2000)

\begin{abstract}
Five days after implantation with 11-ketotestosterone (KT) female Lythrypnus dalli exhibited elevated urinary KT levels and male-like genital papilla morphology. Papilla length increased, width decreased, and length : width ratio increased. Control fish exhibited increases in papilla length, and length : width ratio on day 3 , but not on day 5 . Changes in the total area of the papilla were not statistically significant. It is suggested that KT mediates genital papilla morphology rapidly and thus may be a useful indicator of circulating KT in $L$. dalli.
\end{abstract}

(C) 2000 The Fisheries Society of the British Isles

Key words: androgens; sex-reversal; genital papilla.

\section{INTRODUCTION}

Teleost fishes exhibit a wide variety of reproductive tactics (Demski, 1984; Grober, 1997), including adult sex change (Warner, 1984; Shapiro, 1989). Studies of sex change in fish have considered sex-allocation strategies (Fischer \& Petersen, 1987; St Mary, 1993), ultimate mechanisms (e.g. size advantage hypothesis) and proximate factors (Ross, 1990; Warner \& Swearer, 1991; Lutnesky, 1994). Protogynous sex change is often regulated by social factors, such as inhibition by a dominant male and social stimulation by other females (Shapiro, 1979). Sex change requires correlated changes in a suite of characters, including brain (Grober \& Bass, 1991; Grober \& Sunobe, 1996; Reavis \& Grober, 1999), behaviour (Reavis \& Grober, 1999), hormones (Hourigan et al., 1991), gonads (Nakamura et al., 1984), genitalia (Cole, 1983), and secondary sex characters (e.g. colouration, McIntyre, 1998). Activation of socially regulated sex change has been hypothesized to occur via the hypothalamic-pituitarygonadal (HPG) axis (Grober, 1997). Partial or complete sex change may be induced by steroid treatment (Reinboth, 1985), and in field populations, circulating plasma levels of these steroids change shortly after changes in behaviour (Godwin \& Thomas, 1993) and hypothalamic neuropeptides [arginine vasotocin (AVT); Grober \& Bass, 1991; Grober \& Sunobe, 1996; Godwin et al., 2000].

TAuthor to whom correspondence should be addressed. Tel.: 602 543-6939; Fax: 602 543-6073; email: mgrober@asu.edu 

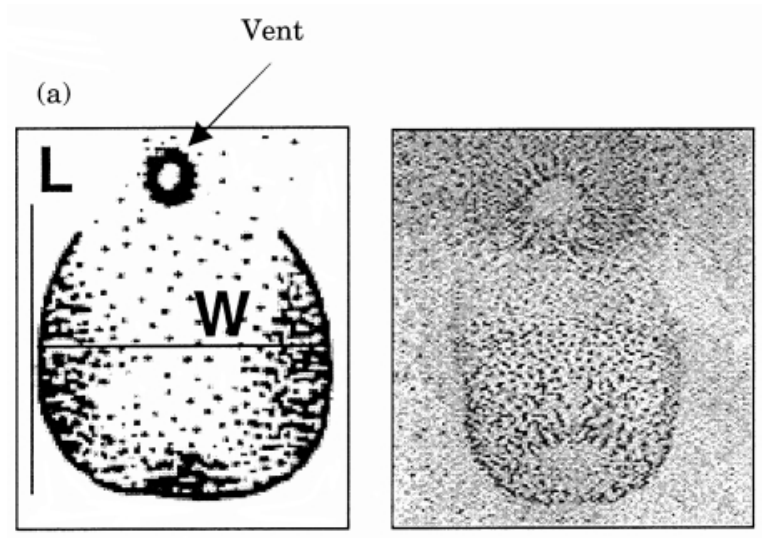

(b)
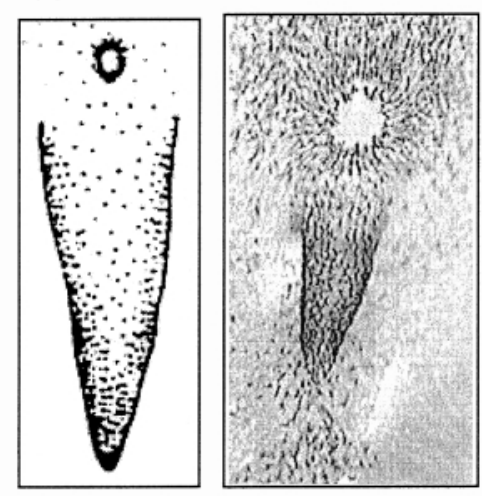

FIG. 1. Sexual dimorphism of the genital papilla of Lythrypnus dalli. Drawings (left-modified with permission, from St Mary (1993), and photographs (right) of female (a) and male (b) papillae. The location of the vent is shown by the arrow, and measurements of length (L) and width (W) of the papilla are indicated.

Reavis \& Grober (1999) proposed an integrative model for sex change in Lythrypnus dalli (Gilbert). This model correlates behavioural changes with physiological changes, and places them in a temporal framework, within which explicit hypotheses can be tested. The behavioural aspects of this model are well understood and have been supported by studies both in the laboratory and in the field. They include a dominance phase, a quiescent phase (which may correspond to changes in gonads, steroids and external genitalia), and a courtship phase (sex change is completed when the fish courts and spawns as a male). The physiological components of the model include changes in the brain, gonads, steroid profiles, and external genitalia. The present long-term goal is to investigate further the relationships among these components, in order to understand the timing of morphological and physiological changes and the way in which they integrate with changes in behaviour. The present study focuses on the role of gonadal steroids.

Changes in steroid profiles are associated with sex change, and the effects of steroid hormones on the sex change process have been studied extensively. In teleosts, many sexually dimorphic characters are androgen dependent (Borg, 1994). These characters include colouration (Reinboth, 1978), spine length (Egami, 1959), sword length (Baldwin \& Goldin, 1939), sonic muscle structure (Brantley et al., 1993), tooth formation (Takeuchi, 1967), and external genitalia (Grobstein, 1940, 1942a,b; Egami, 1959). However, in most cases, these effects have been examined in gonochoristic fish. This study used the hermaphroditic fish $L$. dalli to examine the relationship between androgens and the external genitalia, the genital papilla. This structure is located on the ventral surface of the fish, just posterior to the vent, and is sexually dimorphic (Fig. 1). Females have papillae that are short, wide and blunt. Male papillae are long and thin with a tapered end (St Mary, 1993). During complete sex change, the morphology of the genital papilla shifts from female-typical to male-typical in about 7 days (Reavis \& Grober, 1999). 
Implants of 11-ketotestosterone (KT) were used to manipulate androgen levels and examine the effects on the genital papilla. KT was chosen because it is the most potent fish androgen (Reinboth, 1978), high levels of KT are associated with the expression of sexually dimorphic characters in fish (Oliveira, 1995), and KT levels increase with sex change (Nakamura et al., 1984). Moreover, KT is present in L. dalli (M. S. Grober \& A. V. M. Canario, unpubl. data) and the conversion of $\mathrm{KT}$ into other steroids in vivo has not been reported. The hypothesis was that gonadal steroids mediate genital papilla morphology and it was predicted that female $L$. dalli implanted with KT would develop male-like papilla morphology.

\section{MATERIALS AND METHODS}

The bluebanded goby Lythrypnus dalli is a small goby (adult $L_{\mathrm{S}}=18-45 \mathrm{~mm}$ ) that inhabits rocky reefs from Morro Bay, California to the Sea of Cortez (Miller \& Lea, 1972). They live in mixed-sex social groups at high densities (to $25 \mathrm{~m}^{-2}$ ). Individuals can exhibit dramatic sexual plasticity, including the maintenance of both testicular and ovarian tissue, but they behave as sequential, protogynous hermaphrodites (St Mary, 1993, 1994). Most males derive from females that have undergone sex change (St Mary, 1994). Successful males maintain gonads that are purely testicular, defend nest sites and provide sole parental care of eggs. The sexual plasticity of these fish and their small adult size, make them excellent models for investigating multiple aspects of sex reversal and sexual differentiation including the effects of androgens.

L. dalli were collected using slurp guns or quinaldine sulphate (Sigma Chemical) from the area of Bird Rock, Santa Catalina Island, California (CF\&G Permit No. 802002-02) in May 1998. Experiments were conducted in July and August 1998. All fish were housed in aquaria at Arizona State University West, kept on a 14L : 10D cycle (using fluorescent lighting), at $18-24^{\circ} \mathrm{C}$ and fed a commercially prepared marine flake food.

All fish initially had genital papillae with female typical morphology (as described above). Fish with this morphology have $>95 \%$ ovarian tissue and mate only as females (St Mary, 1993). The fish were divided into one experimental group and two control groups. The experimental group received KT implants $(n=8)$. One control group did not receive implants $(n=10)$, and the other received cholesterol implants $(n=7)$. Cholesterol was chosen as a control for the implant process because steroid hormones are cholesterol derivatives, and this control has been used in previous studies (Grober et al., 1991). Three millimetre diameter implant pellets of pure crystalline KT (Sigma Chemical) or cholesterol (Sigma Chemical) were made using a pellet press (Parr), and were cut into 16 approximately equal pieces.

The implant procedure was as follows: fish were anaesthetized using tricaine methanesulphonate (MS-222, Sigma Chemical; 1-10,000 dilution in sea water). Incisions were made anterior and lateral to the vent and the pellets were inserted just inside the body cavity. The incisions were sealed with a commercial cyanoacrylate adhesive, and one pectoral fin was clipped to identify each fish by treatment group. The fish were placed in sea water and allowed to recover (3-5 min). Throughout the experiment, all fish were housed in individual aquaria and were isolated visually to prevent potentially variable social interactions that could have had a dramatic impact on the results. The order of implantation and the assignment of each fish to a treatment group were haphazard.

Five days was chosen as an appropriate length of time for treatment based on one test fish that was implanted with KT and measured until day 10 . The length : width ratio of the genital papilla of this fish increased up to day 5 , but no further changes occurred up to day 10 (data not shown). On days 0 (the day of implant/isolation), 3, and 5, fish were anaesthetized (as described above). On day 0 , the reproductive condition of each fish was noted and 19 of 25 were visibly gravid. Standard length and body weight of each fish 
TABLE I. Measurements of standard length $\left(L_{S}\right)$, damp weight, and genital papilla (GP) length, width, and area are shown for the 11-ketotestosterone (KT) implant, cholesterol implant, and no implant groups of female Lythrypnus dalli

\begin{tabular}{|c|c|c|c|c|c|}
\hline & $\begin{array}{c}L_{\mathrm{S}} \\
(\mathrm{mm})\end{array}$ & $\begin{array}{l}\text { Weight } \\
\text { (g) }\end{array}$ & $\begin{array}{l}\text { GP length } \\
(\mathrm{mm})\end{array}$ & $\begin{array}{l}\text { GP width } \\
\text { (mm) }\end{array}$ & $\begin{array}{c}\text { GP area } \\
\left(\mathrm{mm}^{2}\right)\end{array}$ \\
\hline \multicolumn{6}{|l|}{ KT } \\
\hline Day 0 & $25 \cdot 63(0 \cdot 70)$ & $0 \cdot 25(0 \cdot 02)$ & $0 \cdot 55(0 \cdot 05)$ & $0 \cdot 57(0 \cdot 59)$ & $0 \cdot 37(0 \cdot 06)$ \\
\hline Day 3 & - & - & $0 \cdot 68(0 \cdot 03)$ & $0 \cdot 49(0 \cdot 03)$ & $0 \cdot 41(0.04)$ \\
\hline Day 5 & $25 \cdot 35(0 \cdot 64)$ & $0 \cdot 23(0 \cdot 02)$ & $0 \cdot 70(0 \cdot 02)$ & $0 \cdot 44(0 \cdot 03)$ & $0 \cdot 36(0 \cdot 04)$ \\
\hline \multicolumn{6}{|l|}{ Cholesterol } \\
\hline Day 0 & $27 \cdot 30(0 \cdot 68)$ & $0 \cdot 31(0 \cdot 02)$ & $0 \cdot 65(0 \cdot 03)$ & $0 \cdot 61(0 \cdot 03)$ & $0 \cdot 48(0 \cdot 04)$ \\
\hline Day 3 & - & - & $0.66(0.02)$ & $0.58(0 \cdot 04)$ & $0.44(0.04)$ \\
\hline Day 5 & $26 \cdot 97(0 \cdot 67)$ & $0 \cdot 29(0 \cdot 02)$ & $0 \cdot 66(0.03)$ & $0 \cdot 60(0 \cdot 02)$ & $0.42(0.03)$ \\
\hline \multicolumn{6}{|l|}{ No implant } \\
\hline Day 0 & $25 \cdot 84(0 \cdot 77)$ & $0 \cdot 25(0 \cdot 02)$ & $0 \cdot 57(0 \cdot 02)$ & $0 \cdot 59(0 \cdot 01)$ & $0 \cdot 41(0 \cdot 02)$ \\
\hline Day 3 & - & - & $0 \cdot 64(0 \cdot 03)$ & $0 \cdot 56(0 \cdot 02)$ & $0 \cdot 40(0 \cdot 02)$ \\
\hline Day 5 & $26 \cdot 11(0 \cdot 71)$ & $0 \cdot 24(0 \cdot 02)$ & $0 \cdot 67(0 \cdot 03)$ & $0 \cdot 58(0 \cdot 02)$ & $0 \cdot 45(0 \cdot 03)$ \\
\hline
\end{tabular}

Values shown are group means ( \pm S.E.) on days 0 and 5 for $L_{\mathrm{S}}$ and damp weight, and on days 0,3 , and 5 for papilla measurements.

were measured on day 0 and day 5 (Table I). Following anaesthetization on days 0,3 , and 5, an image of the genital papilla of each fish was captured using a Zeiss microscope and Scion image version 1.62a (modified from NIH Image, Wayne Rasband), and calibrated against a millimetre ruler. From these images, the length, width (at midlength), and area of the genital papillae were measured (Table I). Length and width were measured by drawing a line through the papilla (Fig. 1). Area was measured by tracing the outside margin of the papilla (Table I). Measurements of papilla images were made without knowledge of the treatment to which the fish had been subjected. Papilla length and width measurements of each fish at days 0,3 , and 5 were used to calculate the length: width ratio of the papilla, which provides good characterization of male and female papillae. A female genital papilla has a blunt end and a length : width ratio close to 1 (the mean for all fish in this study on day $0=1 \cdot 00$ ). A male papilla has a tapered end with a larger length: width ratio $(\geq 1 \cdot 4)$.

On day 5, all fish were killed with excess MS 222 and pellets were removed from the implanted fish. One implanted fish, from which the pellet could not be recovered, was not used in our analyses. Gonads, accessory gonadal structures, and brains from these fish are being analyzed currently.

On day 5, a $500 \mathrm{ml}$ water sample was collected from the tank of each fish and assayed for urinary KT. Urinary androgen levels are correlated positively and temporally with plasma androgen levels in rainbow trout Oncorhynchus mykiss (Walbaum) (Scott \& Liley, 1994). Steroids were extracted from these samples using LiChrolut (Merck) solid-phase $\mathrm{C}_{18}$ matrix cartridges (Sep-Pack ${ }^{\mathbb{R}}$, Waters), previously activated with $4 \mathrm{ml}$ of ethanol followed by $4 \mathrm{ml}$ of distilled water. Extracts were eluted twice with $2 \mathrm{ml}$ of ethanol and dried under nitrogen. Free, glucuronidated and sulphated fractions were obtained using methodologies described by Scott \& Canario (1992) and Canario \& Scott (1989). All fractions were dissolved in $1 \mathrm{ml}$ phosphate buffer $(0 \cdot 1 \mathrm{M}, \mathrm{pH} 7 \cdot 6)$ containing gelatine $(1 \mathrm{~g}$ $1^{-1}$ ) and assayed by radioimmunoassay (RIA). The antiserum was a kind donation of Dr D. E. Kime (University of Sheffield, U.K.) and its specificity characteristics have been published (Kime \& Manning, 1982). The limit of detection of the RIAs was $5 \mathrm{pg} / \mathrm{water}$ sample. Intra-assay and inter-assay precision (coefficient of variation) were, respectively, $8 \cdot 2 \%$ and $11 \cdot 6 \%$ for $\mathrm{KT}$. 
All statistical analyses were performed using Statview 4.5 (Abacus Concepts Inc.). Differences among groups in changes in standard length, body weight, and papilla length, width, length : width ratio, and area were determined using ANOVA. Where differences were significant among groups, post hoc analyses were performed using Scheffé tests. In all ANOVAs in which comparisons were made between treatment groups (with the exception of water KT levels), the change in a variable was used, rather than its actual value, because there is a great deal of individual variation in the traits measured. By using the change in a variable, the effect of treatment on an individual could be examined, regardless of its initial condition. Changes in the genital papilla over the course of the experiment were examined using ANOVA to determine differences in length : width ratio $v$. day, within each group, and linear regressions of genital papilla length, width and length : width ratio $v$. days of treatment for each treatment group.

\section{RESULTS}

On day 5, all KT implant fish had genital papillae with a male-like appearance. The papillae of cholesterol implant and no implant fish retained their femaletypical appearance (Fig. 2). Changes in the genital papilla of the KT group included an increase in length, a decrease in width, and an increase in length : width ratio. At the start of the experiment, all fish had genital papillae with a length : width ratio $<1 \cdot 35$. The length : width ratio of the papillae of fish in the no implant and cholesterol implant groups remained $<1.35$ at the end of this study (mean $=1 \cdot 15 \pm 0 \cdot 04$, and $1 \cdot 10 \pm 0 \cdot 04$ for no implant and cholesterol implant groups, respectively). The KT implant group had papillae with a length: width ratio $\geq 1.42$ on day 5 , with the exception of one fish (mean $=1.63 \pm 0.09$ for all KT fish, $1.69 \pm 0.08$ excluding this fish). KT implant fish exhibited a substantial increase in length of the genital papilla $(F=3 \cdot 16$, $P=0.06$; mean $=0.15 \pm 0.038 \mathrm{~mm}$ ) compared with fish in either control group (Fig. 3; mean $=0.016 \pm 0.040 \mathrm{~mm}$ for cholesterol implant fish, $0.098 \pm 0.034 \mathrm{~mm}$ for no implant fish). In post hoc analysis, the KT and cholesterol implant groups were different at $P=0 \cdot 06$. Differences between the KT and no implant groups, and the no implant and cholesterol implant groups were not significant $(P=0.55$ and $0 \cdot 31$, respectively). Change in genital papilla width (Fig. 3) was significant between groups $(F=4 \cdot 77, P=0 \cdot 02)$, with $\mathrm{KT}$ implant fish showing a decrease in the width of the genital papilla (mean $=-0 \cdot 13 \pm 0.04 \mathrm{~mm}$ for KT implant $v$. $-0.01 \pm 0.02 \mathrm{~mm}$ for cholesterol and $-0.001 \pm 0.02 \mathrm{~mm}$ for no implant). Post hoc analysis showed significant differences between the KT and no implant groups ( $P=0.03)$, but not between the KT and cholesterol implant groups, or the no implant and cholesterol implant groups (although the differences for KT $v$. cholesterol were dramatic, $P=0.08$ ). Changes in the length: width ratio (Fig. 3) of the genital papilla were highly significant between groups $(F=14 \cdot 24, P=0 \cdot 0001)$. Differences were significant between the KT and no implant groups $(P=0.001)$, and the $\mathrm{KT}$ and cholesterol implant groups $(P=0.0003)$, but not between the no implant and cholesterol implant groups $(P=0 \cdot 60)$. There were significant differences in KT levels between the treatment groups (Fig. $4 ; F=5 \cdot 6, P=0 \cdot 01$ ), with the KT implant group being significantly different from both the no implant and cholesterol implant group $(P=0.02$ and $0 \cdot 04$, respectively). The no implant and cholesterol implant groups had similar KT levels $(P=0 \cdot 99)$. 


\section{No implant Cholesterol}
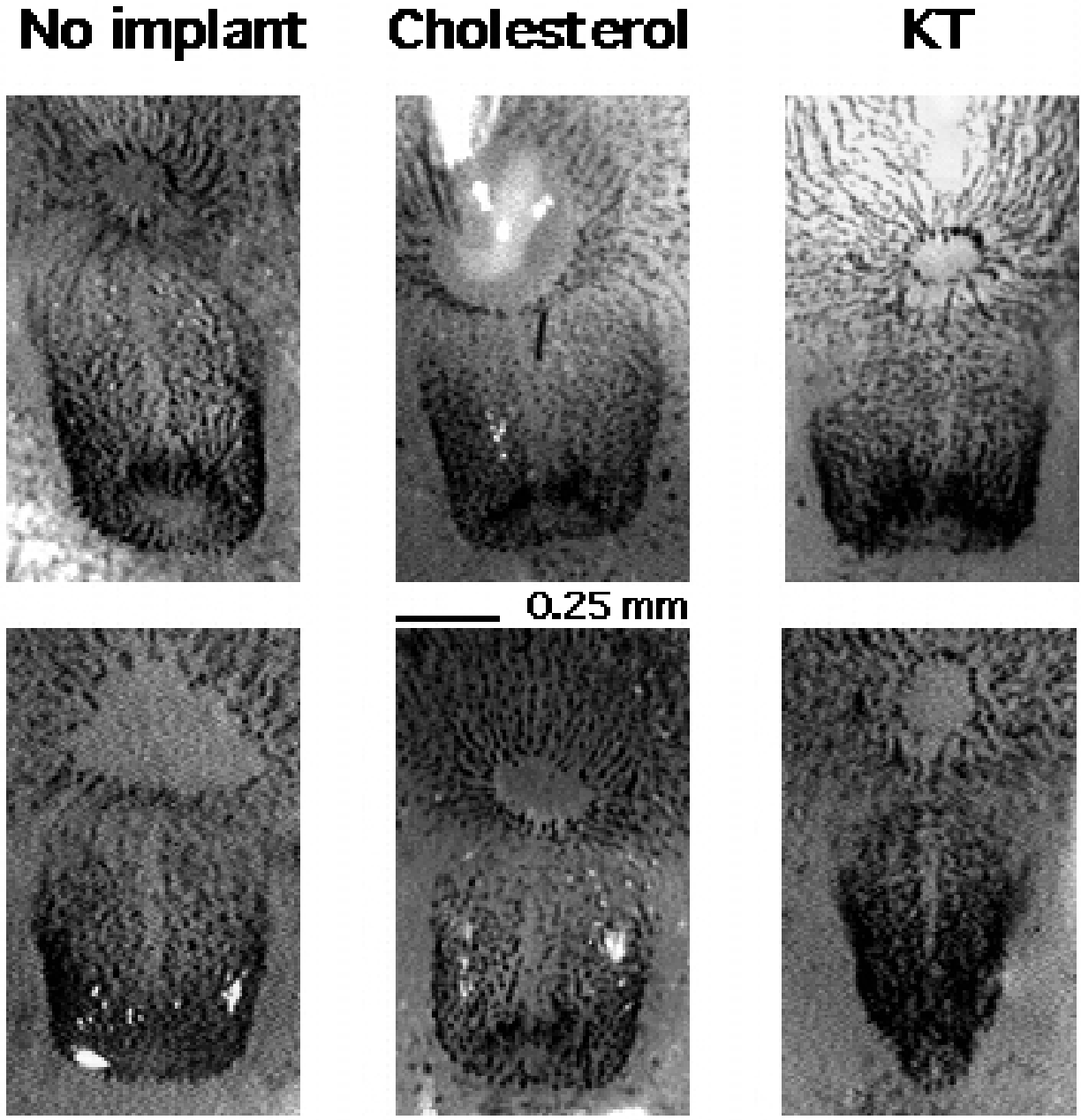

FIG. 2. Genital papillae of one Lythrypnus dalli from the no implant, cholesterol implant, and 11-ketotestosterone (KT) implant groups on days 0 (above) and 5 (below).

Length : width ratio $v$. day of treatment was significant in the KT treatment group between day 0 and day $3(P=0 \cdot 005)$, and day 0 and day $5(P<0 \cdot 0001)$, but not between day 3 and day $5(P=0 \cdot 09)$. For the cholesterol and no implant groups, there were significant differences between day 0 and day $3(P=0 \cdot 04)$, but not between day 3 and day $5(P=0 \cdot 80)$, or between day 0 and day $5(P=0 \cdot 15)$. There were no significant differences between groups for the change in genital papilla area $(F=1 \cdot 41, P=0 \cdot 27)$. Regressions of papilla length $v$. day of treatment were positive and were significant for the KT $\left(P=0.001, r^{2}=0.367\right)$ and no implant $\left(P=0 \cdot 02, r^{2}=0 \cdot 187\right)$ groups, but not for the cholesterol implant group $\left(P=0.70, r^{2}=0 \cdot 008\right)$. For papilla width $v$. day of treatment, all regressions were negative, but the only significant regression was for the KT implant group $\left(P=0.02, r^{2}=0.228\right.$ for KT implant: $P=0.68, r^{2}=0.009$ for cholesterol implant: $P=0.85, r^{2}=0.001$ for no implant). Regressions of the papilla length $:$ width 

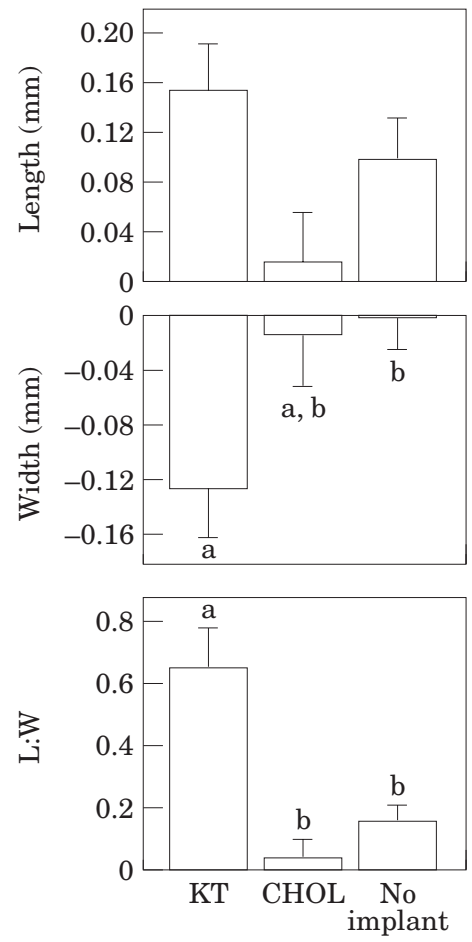

FIG. 3. Changes in the genital papilla of Lythrypnus dalli females 5 days after receiving one of three treatments: 11-ketotestosterone (KT) implant, cholesterol implant (CHOL) or no implant. Changes shown are in length (top), width (centre), and length : width ratio (L: W) (bottom) of the genital papilla. Sample size $(n)=8,7$, and 10 for KT, cholesterol and no implant groups respectively. Letters denote statistical differences $(P<0 \cdot 05)$ and error bars represent standard error.

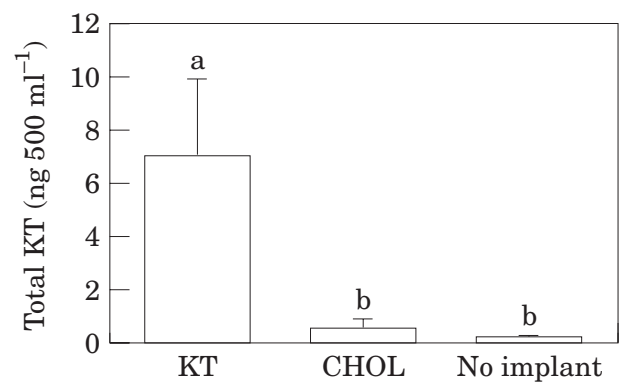

FIG. 4. Levels of 11-ketotestosterone (KT) present in $500 \mathrm{ml}$ water samples taken from aquaria that housed Lythrypnus dalli females for 5 days following one of three treatments: 11-ketotestosterone (KT) implant, cholesterol implant (CHOL) or no implant. Values shown are in nanograms per $500 \mathrm{ml}$ water sample. Letters denote statistical differences $(P<0 \cdot 05)$ and error bars represent standard error.

ratio $v$. day of treatment (Fig. 5) were significant for $\mathrm{KT}(P<0 \cdot 0001)$ and no implant groups $(P=0 \cdot 01)$, but not for the cholesterol implant group $(P=0.63)$. Although the regression for the no implant group was significant, a much greater portion of the variation was explained by the treatment in the KT implant group than in either control group $\left(r^{2}=0 \cdot 64,0 \cdot 012\right.$, and $0 \cdot 19$ for KT implant, 

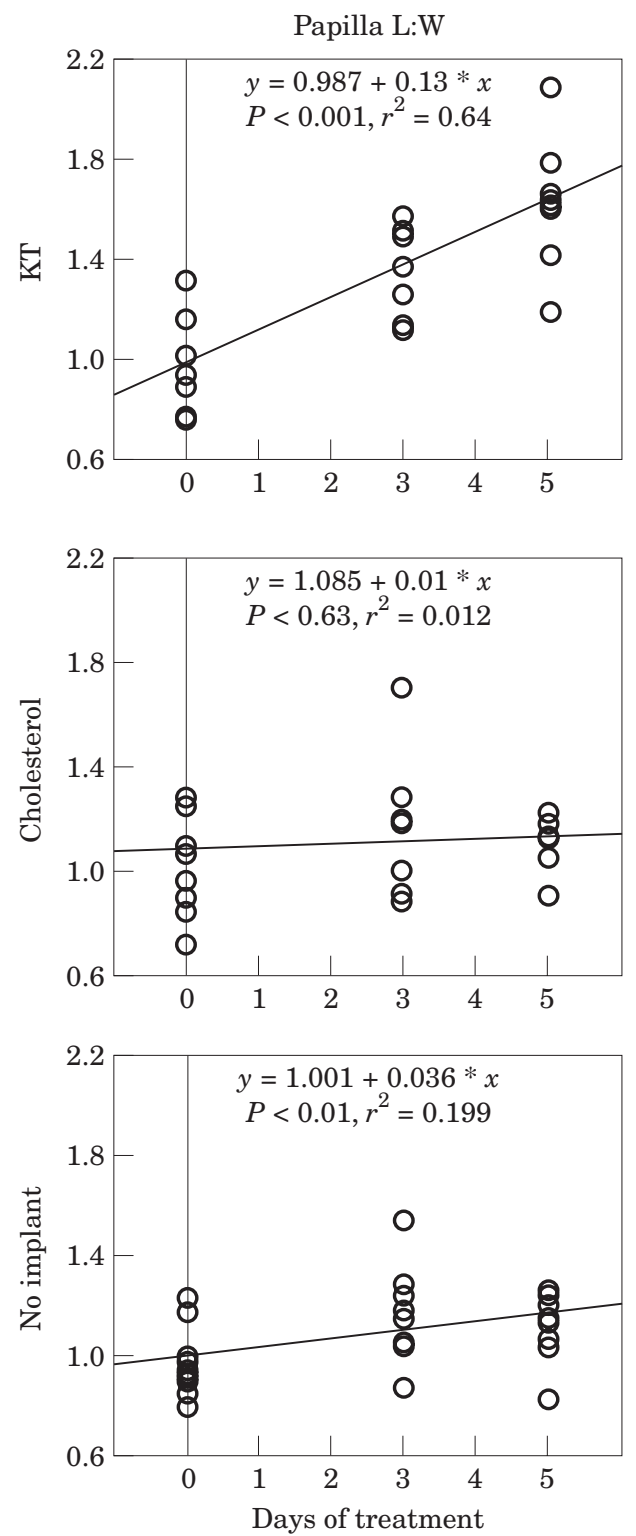

FIG. 5. Regressions of genital papilla length: width ratio (L:W) v. days of treatment for 11-ketotestosterone (KT) implant (top), cholesterol (CHOL) implant (centre) and no implant (bottom) groups of Lythrypnus dalli. $P$ values, regression equations and $r^{2}$ values are indicated.

cholesterol implant, and no implant groups, respectively). The regression of change in papilla length : width ratio $v$. total KT levels from water samples was significant $\left(P=0 \cdot 01, r^{2}=0 \cdot 24\right)$.

None of the changes in genital papilla morphology could be attributed to allometric processes. Neither changes in standard length nor changes in body weight differed significantly between groups over the course of the experiment ( $F=1 \cdot 02, P=0.38$ for standard length: $F=0.87, P=0.43$ for body weight). 


\section{DISCUSSION}

Female $L$. dalli treated with KT exhibited increased levels of KT and male-like genital papillae within 5 days following implantation. All fish in both the cholesterol implant and the no implant groups had papillae that retained their female-typical characteristics. The lack of significant change in the area of the papilla suggests that changes in papilla morphology involve a rearrangement of tissue, rather than a reduction or addition of tissue.

These results support the hypothesis that gonadal steroids mediate genital papilla morphology (Oliveira \& Almada, 1998). Further, it is suggested that while genital papilla morphology may not be a useful indicator of the gonadal allocation of individual $L$. dalli (fish with male morphology may have between 5 and 100\% testicular tissue; St Mary, 1993), it may provide an accurate assessment of the presence of androgens (Oliveira \& Almada, 1998). The use of androgen dependent characters as an assay of steroids is consistent with McIntyre (1998), who gave KT implants to Thalassoma bifasciatum (Bloch) and observed a colour change within 10 days. Furthermore, this colour change was associated with increased plasma levels of KT.

The findings support the sex change model for L. dalli (Reavis \& Grober, 1999), with respect to the timing of changes in gonadal steroid levels relative to genital papilla morphology. Given the dramatic effects of exogenous androgens on the genital papilla, the data are consistent with the idea that, during sex change, androgen levels increase before changes in the papilla and appear to mediate these changes. The results are also consistent with the timing of the quiescent phase exhibited by the sex changing individual. In the most favourable situation, a sex changing fish will establish dominance in 1-2 days, spend about 3-4 days in the quiescent phase, and court for 1-2 days. Sex change is complete in about 6-8 days. Given this timing, changes would be expected in the papilla between 3 and 6 days. The data show that this is enough time for genital papilla changes. Further, because these changes were completed 5 days following implantation, gonadal steroid levels may begin to increase early in sex change, but the effect of these increases may not be observed in the papilla for several days.

The results are consistent also with the work of Egami (1959), who gave injections of testosterone to Pterogobius zonoleucus (Jordan \& Synder) and observed changes in several sexually dimorphic characters including the genital papilla. Although there was an increase in papilla length in these fish, there was no change in the sexual dimorphism of the papilla. This result differs from the present one, and may be due to the length of time after injection at which these fish were observed (30 days). This interval may be too long and some of the effects of the androgen may have been missed.

One KT implant fish had a length : width ratio $<1.42$ on day 5 . This fish did not appear to respond to the treatment as dramatically as the others. One possible explanation for this limited response is that this fish was extremely gravid at the beginning of the experiment, and the presence of well-developed eggs may have constrained the response to KT treatment. Reavis \& Grober (1999) suggested that gravid fish may require extended time in the quiescent phase, to get the present clutch of eggs fertilized, or resorb or eliminate them. 
Interestingly, some fish in the cholesterol implant and no implant groups exhibited ephemeral increases in papilla length. Increases in length : width ratio were significant between day 0 and day 3, but not between day 3 and day 5, or between day 0 and day 5 . This temporary change in genital papilla morphology may be a result of isolation. The social environment plays an extremely important role in determining the sex of these fish, and individuals that have been removed from their social group may perceive an opportunity to change sex (e.g. lack of inhibition by a dominant male). These fish may begin to increase their testicular tissue and androgen levels, resulting in a change in the length : width ratio of the papilla. However, if no mates are available, they may return to their previous condition. This explanation is consistent with the significant regressions of length $v$. day and length : width $v$. day in the no implant group. Moreover, it is supported by the significant increase in length : width ratio seen between days 0 and 3, but no longer seen between days 0 and 5 in the cholesterol and no implant groups. In the KT treatment group, the effect of day on length : width ratio remained significant between days 0 and 5 . Further, even when papilla length increased temporarily, none of the fish in the cholesterol and no implant groups had papillae with the male-typical tapered end.

In order to develop a comprehensive understanding of the sex change process in L. dalli, additional studies are needed. These studies should examine the processes that link early neural and behavioural changes to the increase in gonadal steroids and concomitant changes in the external genitalia.

We thank M. Garcia, A. Perry and D. Cabrera for their help with papilla measurements; J. Miranda for help with Figure 2. G. W. Schuett, K. A. Hughes and the Grober lab reading group from spring 1999, and three anonymous referees for their comments on a previous version of this manuscript. This work was supported by NSF \#IBN-9723817 (MG) and FCT \#331/94 (RO).

\section{References}

Baldwin, F. M. \& Goldin, H. S. (1939). Effects of testosterone propionate on the female viviparous teleost, Xiphopherus helleri Heckel. Proceedings of the Society for Experimental Biology and Medicine 42, 813-819.

Borg, B. (1994). Mini Review: Androgens in teleost fishes. Comparative Biochemistry and Physiology 109 C, 219-245.

Brantley, R. K., Marchaterre, M. A. \& Bass, A. H. (1993). Androgen effects on vocal muscle structure in a teleost fish with inter- and intra-sexual dimorphism. Journal of Morphology 216, 305-318.

Canario, A. V. M. \& Scott, A. P. (1989). Conjugates of ovarian steroids, including $17 a, 20 \beta$-dihydroxy-4-pregnen-3-one (maturation-inducing steroid), accumulate in the urine of a marine teleost, accumulate in the urine of a marine teleost (plaice; Pleuronectes platessa). Journal of Endocrinology 127, R1-R4.

Cole, K. S. (1983). Protogynous hermaphroditism in a temperate zone territorial marine goby, Coryphopterus. Copeia 3, 809-812.

Demski, L. (1984). The evolution of neuroanatomical substances of reproductive behaviour: sex steroid and LHRH-specific pathways including the terminal nerve. American Zoologist 24, 809-830.

Egami, N. (1959). Effect of testosterone on the sexual characteristics of the gobiid fish, Pterogobius zonoleucus. Annotationes Zoologicae Japonenses 32, 123-128.

Fischer, E. A. C. \& Petersen, W. (1987). The evolution of sexual patterns in the seabass. Bioscience 37, 482-489. 
Godwin, J. R. \& Thomas, P. (1993). Sex change and steroid profiles in the protandrous anemone fish Amphiprion melanopus (Pomacentridae, Teleostei). General and Comparative Endocrinology 91, 144-157.

Godwin, J., Sawby, R., Warner, R. R., Crews, D. \& Grober, M. S. (2000). Hypothalamic arginine vasotocin mRNA abundance variation across sexes and with sex change in a coral reef fish. Brain, Behavior and Evolution 55, (in press).

Grober, M. S. (1997). Neuroendocrine foundations of diverse sexual phenotypes in fish. In Sexual Orientation: Toward Biological Understanding (Ellis, L. \& Ebertz, L., eds), pp. 3-20. Westport, CT: Praeger.

Grober, M. S. \& Bass, A. H. (1991). Neuronal correlates of sex/role change in labrid fishes: LHRH-like immunoreactivity. Brain, Behaviour and Evolution 38, 302-312.

Grober, M. S. \& Sunobe, T. (1996). Serial adult sex change involves rapid and reversible changes in forebrain neurochemistry. Neuroreport 7, 2945-2949.

Grober, M., Jackson, I. M. D. \& Bass, A. H. (1991). Gonadal steroids affect LHRH preoptic cell number in a sex/role changing fish. Journal of Neurobiology 22, 734-741.

Grobstein, C. (1940). Effects of testosterone propionate on regeneration of anal fin of adult Platypoecilus maculatus females. Proceedings of the Society for Experimental Biology and Medicine 45, 484- 486.

Grobstein, C. (1942a). Effects of various androgens on regenerating anal fin of adult Platypoecilus maculatus females. Proceedings of the Society for Experimental Biology and Medicine 49, 477-478.

Grobstein, C. (1942b). Endocrine and developmental studies of gonopod differentiation in certain poeciliid fishes II. Effects of testosterone propionate on the normal and regenerating anal fin of adult Platypoecilus maculatus females. Journal of Experimental Zoology 89, 305-328.

Hourigan, T. F., Nakamura, M., Nagahama, Y., Yamauchi, K. \& Grau, E. G. (1991). Histology, ultrastructure, and in vitro steroidogenesis of the testes of two male phenotypes of the protogynous fish, Thalassoma duperrey (Labridae). General and Comparative Endocrinology 83, 193-217.

Kime, D. E. \& Manning, N. J. (1982). Seasonal patterns of free and conjugate androgens in the brown trout, Salmo trutta. General and Comparative Endocrinology 48, 222-231.

Lutnesky, M. (1994). Density-dependent protogynous sex change in territorial-haremic fishes: models and evidence. Behavioral Ecology 5, 375-383.

McIntyre, K. K. (1998). Arginine vasotocin in the preoptic area of the bluehead wrasse and the effects of 11-ketotestosterone. M.S. thesis, Arizona State University.

Miller, D. J. \& Lea, R. N. (1972). Guide to the coastal marine fishes of California. California Department of Fish and Game, Fish Bulletin 157, 235 pp.

Nakamura, M. K., Yamauchi, Y., Naghama \& Grau, E. G. (1984). Endocrine-regulated morphological changes in the gonad during sex reversal in protogynous wrasse. Zoological Science 1, 967.

Oliveira, R. F. (1995). Etologia social e endocrinologia comportamental da Tilapia mossambica(Teleostei, Cichlidae). PhD dissertation, University of Lisbon.

Oliveira, R. F. \& Almada, V. C. (1998). Androgenization of dominant males in a cichlid fish: androgens mediate the social modulation of sexually dimorphic traits. Ethology 104, 841-858.

Reavis, R. H. \& Grober, M. S. (1999). An integrative approach to sex reversal: social, behavioural and neurochemical changes in Lythrypnus dalli (Pisces). Acta Ethologica. 2, 51-60.

Reinboth, R. (1978). Bioassay for androgenic effects of various $C_{19}$ steroids in the juvenile cichlid fish. General and Comparative Endocrinology 34, 85-86.

Reinboth, R. (1985). Ambosexuality in teleosts - a challenge to endocrinologists. In Current Trends in Comparative Endocrinology (Lofts, B. \& Holmes, W. N., eds), pp. 579-581. Hong Kong: University of Hong Kong Press.

Ross, R. M. (1990). The evolution of sex-change mechanisms in fishes. Environmental Biology of Fishes 29, 81-93. 
Scott, A. P. \& Canario, A. V. M. (1992). 17a,20 $\beta$-Dihydroxy-4-pregnen-3-one 20-sulphate; a major new metabolite of the teleost oocyte maturation-inducing steroid. General and Comparative Endocrinology 85, 91-100.

Scott, A. P. \& Liley, N. R. (1994). Dynamics of excretion of $17 a, 20 \beta$-Dihydroxy-4pregnen-3- one 20-sulphate and of the glucuronides of testosterone and $17 \beta$ oestradiol, by urine of reproductively mature male and female rainbow trout (Oncorhynchus mykiss). Journal of Fish Biology 44, 117-129.

Shapiro, D. Y. (1979). Social behavior, group structure and the control of sex reversal in hermaphrodite fish. Advances in the Study of Behavior 10, 43-102.

Shapiro, D. Y. (1989). Sex change as an alternative life-history style. In Alternative Life-History Styles of Animals (Bruton, M. N., ed.), pp. 177-195. Dordrecht: Kluwer Academic Publishers.

St Mary, C. M. (1993). Novel sexual patterns in two simultaneously hermaphroditic gobies, Lythrypnus dalli and Lythrypnus zebra. Copeia 4, 1062-1072.

St Mary, C. M. (1994). The determinants of sex allocation patterns and the maintenance of simultaneous hermaphroditism in the blue-banded goby (Lythrypnus dalli) and the zebra goby (Lythrypnus zebra). PhD dissertation, UMI Dissertation Services, Ann Arbor Michigan.

Takeuchi, K. (1967). Large tooth formation in female medaka, Oryzias latipes, given methyl testosterone. Journal of Dental Research 46, 750.

Warner, R. R. (1984). Mating behavior and hermaphroditism in coral reef fishes. American Scientist 72, 128-136.

Warner, R. R. \& Swearer, S. E. (1991). Social control of sex change in the bluehead wrasse, Thalassoma bifasciatum (Pisces: Labridae). Biological Bulletin 181, 199204. 